\title{
Mechanisms of TIGIT-driven immune suppression in cancer
}

\author{
Sema Kurtulus ${ }^{1 *}$, Kaori Sakuishi ${ }^{2}$, Huiyuan Zhang ${ }^{1}$, Nicole Joller ${ }^{1}$, Dewar Tan ${ }^{1}$, Mark Smyth ${ }^{3}$, Vijay Kuchroo ${ }^{1}$, \\ Ana Anderson ${ }^{1}$ \\ From Society for Immunotherapy of Cancer 29th Annual Meeting \\ National Harbor, MD, USA. 6-9 November 2014
}

TIGIT is a co-inhibitory molecule that limits T cell proliferation and activation. TIGIT expression has been recently shown to identify a subset of regulatory $\mathrm{T}$ cells (Treg) that specifically suppresses Th1 and Th17 responses; however its role in tumor immunity has not been examined. Here, we determined whether TIGIT has a role in the suppression of anti-tumor immune responses. We found that TIGIT is highly up-regulated on Treg and CD8+ tumorinfiltrating lymphocytes (TILs) in multiple pre-clinical cancer models. Importantly, TIGIT expression is strongly associated with expression of other co-inhibitory molecules; PD-1, Tim-3 and Lag-3 and with production of IL-10 in Treg and CD8+ TILs. Moreover, TIGIT+ CD8+ TILs display an exhausted phenotype determined by decreased production of IL- 2 and TNF- $\alpha$. To understand whether TIGIT acts as a checkpoint in anti-tumor response, we monitored growth of implanted B16 melanoma in TIGIT $^{-1-}$ mice and found that absence of TIGIT significantly delayed tumor growth. As TIGIT is expressed on both T cells (Treg and CD8+) and NK cells in cancer, we addressed the role of TIGIT in these subsets in driving immune suppression. Our data indicate that TIGIT may play a dominant role in Treg in that deficiency of TIGIT in Treg alone results in better control of tumor growth and a heightened proliferative response in the draining lymph nodes and spleens of tumor-bearing mice. Finally, we show that a TIGIT blocking antibody can be used therapeutically to decrease tumor growth and that blockade of TIGIT synergizes with Tim-3 blockade to maximally decrease tumor growth. Our study is the first report showing that TIGIT acts as an immune checkpoint in cancer. Importantly, our data indicate that TIGIT and Tim-3 synergize to suppress anti-tumor responses and targeting

${ }^{1}$ Center for Neurologic Diseases Brigham \& Women's Hospital, Boston, MA, USA

Full list of author information is available at the end of the article these two molecules could provide a therapeutic effect on tumor growth.

\section{Authors' details}

${ }^{1}$ Center for Neurologic Diseases Brigham \& Women's Hospital, Boston, MA, USA. ${ }^{2}$ The University of Tokyo, Tokyo, Japan. ${ }^{3}$ Peter MacCallum Cancer Centre, Queensland Institute of Medical Research, Queensland, Australia.

Published: 6 November 2014

doi:10.1186/2051-1426-2-S3-O13

Cite this article as: Kurtulus et al: Mechanisms of TIGIT-driven immune suppression in cancer. Journal for ImmunoTherapy of Cancer 2014 2(Suppl 3):013.
Submit your next manuscript to BioMed Central and take full advantage of:

- Convenient online submission

- Thorough peer review

- No space constraints or color figure charges

- Immediate publication on acceptance

- Inclusion in PubMed, CAS, Scopus and Google Scholar

- Research which is freely available for redistribution

Submit your manuscript at www.biomedcentral.com/submit
() Biomed Central 